\title{
Determination of 17 Perfluoroalkyl Substances in Sediments Using Automated Solid Phase Extraction and Ultrahigh-Performance Liquid Chromatography-Tandem Mass Spectrometry
}

\author{
Grażyna Gałęzowska ${ }^{1}$ (D . Justyna Rogowska ${ }^{1}$ Ewa Olkowska ${ }^{1}$. Lidia Wolska ${ }^{1}$
}

Received: 19 August 2019 / Revised: 26 May 2020 / Accepted: 16 June 2020 / Published online: 30 June 2020

(c) The Author(s) 2020

\begin{abstract}
Perfluoroalkyl substances (PFASs) are used in a variety of industrial and household applications. Unfortunately, they are released to the environment including aquatic ecosystems and undergo accumulation processes (e.g., in sediment). Due to these aspects but also toxicity, PFASs can pose a threat to the environment and humans, so their determination (mainly with liquid chromatography) in environmental samples is very important. In this study, a new analytical procedure is shown which allows the determination of 17 PFASs (13 carboxylic and 4 sulfonic acids) in sediment using ultrahigh-performance liquid chromatography and tandem mass spectrometry detection (UHPLC-MS/MS). Extracts were cleaned up by automated solid phase extraction using a commercially available weakly basic secondary and tertiary ammonium polymeric anion exchange sorbent. The method precision range was $0.29-9.8 \%$ for all PFASs. Recoveries of extraction for automated system were acceptable (for all PFASs 60-105\%) and better than manual extraction. The method detection limit range was from 0.090 to $3.7 \mathrm{pg} \mathrm{g}^{-1}$ dry weight (d.w.) of sediment. The proposed method is rapid, sensitive and suitable for determination of up to 17 PFASs in sediment. These are the first studies in the area of the mouth of the Vistula River. Generally, in most collected sediments samples no analytes were detected above the method detection limits.
\end{abstract}

Keywords Perfluoroalkyl substances · PFASs $\cdot$ Sediments · UHPLC-MS/MS · Chromatographic analysis

\section{Introduction}

Perfluoroalkyl substances (PFASs) have been produced since the 1950s [1]. Presently, about 600 synthetic PFASs are commercially available [2]. Because of versatility, they are used in a variety of industrial and household applications, including stain-resistant coatings for fabrics and carpets, oilresistant coatings for paper products approved for food contact, fire-fighting foams and insecticide formulations [3, 4].

A number of studies documented that PFASs are ubiquitously present in the environment and living organisms [5-7]. The main sources of PFASs in the aquatic environment are discharged from wastewater treatment plants and urban surface runoff water. Due to high solubility of PFASs

Grażyna Gałęzowska

grazyna.galezowska@gumed.edu.pl

1 Department of Environmental Toxicology, Faculty of Health Science, Medical University of Gdansk, 23A Debowa Str., 80-204 Gdańsk, Poland in water, research mostly focuses on contamination of surface or drinking water with these compounds $[8,9]$. However, sediments can be a reservoir of secondary pollutants. As a result of re-suspension caused by the circulation of water and the activity of benthic or bentho-eating organisms, pollution deposited in the sediments can return back into the water. A study by Higgins and Luthy [10] showed that sediment sorption of PFASs depends on factors such as organic carbon content, $\mathrm{pH}$, and chemical structure of the compounds. Chen et al. [5] reported that strong sorption of perfluoroalkyl sulfonic acids (PFSAs) to settling sedimentary particles is expected to be the principal removal mechanism in surface water bodies, while sorption of perfluoroalkyl carboxylic acids (PFCAs) on suspended solids is relatively weak and reversible. Therefore, it is important to investigate the content of PFASs compounds not only in water but also in sediments.

Because of widespread occurrence of PFASs in the environment and their ability to undergo bioaccumulation, they have been the topic of increasing scientific interest [11] Additionally, properties (e.g., toxicity) of these compounds 
pose a threat to the environment and living organisms. PFASs have been found to be tumorigenic, carcinogenic, hypo-lipidemic and have adverse effects on the reproductive outcome [12-14]. The physical and chemical properties of PFASs limit the methods which can be used for their determination. For example, their low volatility eliminates the possibility of using gas chromatography/mass spectrometry (GC/MS) [15]. GC can be used only for the direct determination of the neutral, volatile per and poly-fluoroalkyl substances including several precursors of PFSAs and PFCAs. Currently, the preferred technique for a quantitation determination of PFASs in environmental samples is liquid chromatography coupled with tandem mass spectrometry (LC-MS/ MS) [16].

Nowadays, the available analytical methods provide isolation and separation for about 14 PFASs including $\mathrm{C}_{4^{-}}$to $\mathrm{C}_{14}$-perfluoro acid and $\mathrm{C}_{4}$ - to $\mathrm{C}_{8}$-perfluoro sulfonate $[3,17$, 18]. The list of determined PFASs should be supplemented with other applied compounds. Currently, 17 PFASs are available (also perfluoro- $n$-hexadecanoic acid, perfluoro$n$-octadecanoic acid and sodium perfluoro-1-decanesulfonate). For these compounds, the new analytical method which provides their separation is needed. Additionally, analyses of environmental samples will allow the determination of eventual, not yet analyzed, PFASs compounds that appear in sediments.

The aim of our study was to develop a rapid and efficient analytical procedure for the determination of PFCAs and PFSAs in sediments using SPE and UHPLC-MS/MS techniques.

\section{Experimental}

\section{Standards and Solvents}

The standard solution mixtures $\left(2000 \mathrm{ng} \mathrm{mL}^{-1}\right)$ of PFASs including perfluoro- $n$-butanoic acid (PFBA), perfluoro$n$-pentanoic acid (PFPeA), perfluoro- $n$-hexanoic acid (PFHxA), perfluoro- $n$-heptanoic acid (PFHpA), perfluoro$n$-octanoic acid (PFOA), perfluoro- $n$-nonanoic acid (PFNA), perfluoro- $n$-decanoic acid (PFDA), perfluoro- $n$-undecanoic acid (PFUdA), perfluoro- $n$-dodecanoic acid (PFDoA), perfluoro- $n$-tridecanoic acid (PFTrDA), perfluoro- $n$-tetradecanoic acid (PFTeDA), perfluoro- $n$-hexadecanoic acid (PFHxDA), perfluoro- $n$-octadecanoic acid (PFODA), potassium perfluoro-1-butanesulfonate (PFBS), sodium perfluoro1-hexanesulfonate (PFHxS), sodium perfluoro-1-octanesulfonate (PFOS), sodium perfluoro-1-decanesulfonate (PFDS) were obtained from Wellington Laboratories (Canada).

The isotopically labeled PFASs standard solutions (2000 $\mathrm{ng} \mathrm{mL}^{-1}$ ) including sodium perfluoro-1-hexane $\left[{ }^{18} \mathrm{O}_{2}\right]$ sulfonate (MPFHxS), sodium perfluoro- $n-\left[1,2,3,4-{ }^{13} \mathrm{C}_{4}\right]$ octanoic acids (MPFOA), perfluoro- $n-\left[{ }^{13} \mathrm{C}_{4}\right]$ butanoic acids (MPFBA), perfluoro- $n-\left[1,2-{ }^{13} \mathrm{C}_{2}\right]$ hexanoic acid (MPFHxA), perfluoro-1-[1,2,3,4- $\left.{ }^{13} \mathrm{C}_{4}\right]$ octanesulfonate (MPFOS), perfluoro- $n$ - $\left[1,2-{ }^{13} \mathrm{C}_{2}\right]$ decanoic acid (MPFDA), perfluoro$n$-[1,2- $\left.{ }^{13} \mathrm{C}_{2}\right]$ undecanoic acid (MPFUdA), perfluoro- $n$ $\left[1,2-{ }^{13} \mathrm{C}_{2}\right]$ dodecanoic acid (MPFDoA) were also supplied by Wellington Laboratories (Canada). Methanol (MeOH) LC-MS grade and ammonium acetate $\left(\mathrm{NH}_{4} \mathrm{Ac}\right) \mathrm{MS}$ grade were purchased from Merck (Germany). Ultrapure water $\left(\mathrm{H}_{2} \mathrm{O}\right)$ was produced using the Hydrolab system (Poland).

Different working standard solutions were prepared by appropriate dilution in methanol to obtain concentration range $0.05-1000 \mathrm{ng} \mathrm{mL}^{-1}$ for each analytes. For labeled compounds, stock solution was prepared also in methanol to obtain concentration of $50 \mathrm{ng} \mathrm{mL}^{-1}$ and they were used as internal standards (ISs).

\section{Sample Handling and Preparation}

The sediment samples were collected at various locations in the area of the Gulf of Gdansk (southern part of the Baltic Sea) including 17 samples from the Vistula River estuary. Samples were taken with a Van Veengrab sampler from a research vessel in 2014.

All samples were lyophilized. Five grams of dry sediment was alkalized by $\mathrm{NaOH}$ in $80 \%$ methanol, and $5 \mathrm{ng}$ ISs in $\mathrm{MeOH}$ (mixture of MPFHxS, MPFOS, MPFBA, MPFHxA, MPFOA, MPFDA, MPFUdA and MPFDoA) were added to a tube before extraction. The solid phase extractions (SPEs) were performed by manual system SPE-12G (Baker, USA) and by SmartPrep ${ }^{\circledR}$ Automated Cartridge Extractor (Horizon Technology, USA). The efficiency of systems was compared based on recoveries calculated for all compounds (initial concentration of $0.5 \mathrm{ng} \mathrm{mL}^{-1}$ for each compound). The procedure for extraction of PFASs from sediments and cleanup of extracts was used according to a modified procedure proposed by Yang et al. [4], consisting of weighing of sediment (5 g), sample alkalization with $\mathrm{NaOH}$ in $80 \% \mathrm{MeOH}(1 \mathrm{~h})$, extraction $(10 \mathrm{~mL} \mathrm{MeOH})$ with sonification (30 min), centrifugation (2000 rpm for $5 \mathrm{~min}$ ), supernatant acidification $(1.5 \mathrm{~mL}$ of $200 \mathrm{mM} \mathrm{HCl})$ and then cleanup on SPE column (column conditioning-10 mL of $\mathrm{MeOH}$ followed by $10 \mathrm{~mL}$ of water, sample application- $3 \mathrm{~mL} \mathrm{~min}{ }^{-1}$, washing $-5 \mathrm{~mL}$ of $40 \% \mathrm{MeOH}$, drying, elution-10 $\mathrm{mL}$ of $\mathrm{MeOH}$ ). Before UHPLC analysis, sample was blown down to $1 \mathrm{~mL}$ under a nitrogen stream.

The modifications consisted in the use of a HR-XAW column (Macherey-Nagel, Germany) for further cleanup and change step of ISs addition stage. The interaction of PFASs with stationary phase in HR-XAW columns is similar to interactions in SPE Oasis HLB column (different producers). ISs addition stage was changed for first step until solid 
preparation before extraction. This is more justified due to possible losses of analytes during extraction.

\section{UHPLC-MS/MS Analysis}

Prepared samples were analyzed by ultrahigh-performance liquid chromatography. The Nexera X2UHPLC-MS/MS (Shimadzu Corp., Japan) consists of: two LC-30AD pumps, SiL-30AC autosampler, CTO-20AC column oven, CBM20A communication bus module and mass spectrometer LC-MS8050 with an electrospray ionization with negative ion mode. The chromatographic separation was performed using an Acquity UPLC BEH C18, $1.7 \mu \mathrm{m}, 2.1 \mathrm{~mm}, 100 \mathrm{~mm}$ (Waters, USA) analytical column. The mobile phase consisted of the following 9-min sequence of linear gradients flows of solvent B (methanol) balanced with solvent A ( 0 , 2.5 or $5 \mathrm{mM}$ ammonium acetate in water) at a flow rate of $0.6 \mathrm{~mL} \mathrm{~min}^{-1}$ : $40-65 \%$ B over $0.5 \mathrm{~min}, 65-95 \%$ B over 5 min, isocratic $95 \%$ B for $3.5 \mathrm{~min}$ and finally $95-40 \%$ B over $0.1 \mathrm{~min}$. The injection volume was $2 \mu \mathrm{L}$, and column temperature was $40^{\circ} \mathrm{C}$.

The main parameters used to identify analytes were their retention times and multiple reaction monitoring (MRM) ratio (which were obtained at $1 \mu \mathrm{g} \mathrm{mL}^{-1}$ working standard solutions). Chromatographic data processing was carried out using LabSolution ${ }^{\circledR}$ software (Shimadzu Corp., Japan).

\section{Method Validation}

Ensuring the quality of the measurements results was carried out by [19]:

- Calibration of the LC-MS/MS system,

- Determination of the selected validation parameters based on calibration curves.

- Determination of the selected validation parameters based on real samples analysis with adding PFASs.

The calibration step involves the preparation of calibration curves and calculation of response factor (RF) for internal standards. Eleven working standards solutions have been prepared. Limit of determination (LOD) has been calculated from the parameters of a calibration curve constructed on the basis of the three lowest concentrations of working standards solutions. The limit of determination has been calculated according to the formula:

$\mathrm{LOD}=\frac{3.3 \times s}{a}$,

where $a$ is the slope of the calibration curve, and $s$ is the standard deviation.

In the calculation, we took into account residual standard deviation $\left(s_{x y}\right)$ and standard deviation of the intercept $\left(s_{a}\right)$. Based on $\operatorname{LOD}\left(s_{x y}\right)$ and $\operatorname{LOD}\left(s_{a}\right)$, the mean values (LOD) were calculated. The coefficients of variation (CV) and extended uncertainty $(U)$ were calculated based on standard deviations, and the average area of the chromatographic peaks was obtained during separation of standard mixtures.

The linearity of this method was assessed using standard solutions at eleven different concentrations $(1000,100,50$, $25,12.5,5,1,0.5,0.25,0.1$ and $\left.0.05 \mathrm{ng} \mathrm{mL}^{-1}\right)$.

To check for the matrix effect, three sediment samples were prepared with the addition of labeled standard solution and analyzed using automatic SPE and LC-MS/MS techniques. Based on area of standard peaks, the recoveries [\%] for eight labeled analytes were calculated.

The precision (as relative standard deviation-RSD) of the analytical procedure was evaluated by determining the intraand inter-day RSDs (for sediment 1 with standard mixture of all PFASs at two concentration level: 0.5 and $12.5 \mathrm{ng} \mathrm{mL}^{-1}$ and five repetitions). The intra-day precision is referred to as the repeatability of the assay, while the inter-day precision is referred to as the intermediate precision of the assay. The assay was repeated on 3 days to obtain inter-day precision and recovery values. The recovery of the analytical procedure is the extent to which the test results generated by the procedure and the true value agree. The recovery is expressed as the relative error of measurement. The intraand inter-day recoveries were evaluated.

\section{Results and Discussion}

\section{UHPLC-MS/MS Optimization}

Optimization of LC-MS/MS parameters included $\mathrm{ESI}^{+}$and $\mathrm{ESI}^{-}$to assess the ionization efficiency for each compound. The negative mode was found to provide higher sensitivity and signal intensity than positive ionization mode for all analytes. The quantification and confirmation ions were selected according to precursor ion and its most intense fragment ion. Additionally, the parameters of collision energy (CE), declustering potential ( $Q 1$ and $Q 3$ pre-bias) but also interface, desolvation line and heating block temperatures and gas flows were optimized. The optimization parameter results are shown in Table 1.

Optimization of chromatographic analysis was performed under several different programs of mobile phase gradient. In case of the aqueous part of the mobile phase, a small amount of ammonium acetate $(2.5 \mathrm{mM})$ as additive was enough to obtain sufficient peak shape and high intensities of detector signal (see Fig. 1). The Acquity BEH C18 column was selected for subsequent analysis procedures, since it is recommended for analysis of perfluoroalkyl substances. 
Table 1 Optimization parameters for the monitored ion transitions and triple quadrupole mass spectrometer (MS/MS) operation

\begin{tabular}{|c|c|c|c|c|c|}
\hline \multicolumn{6}{|c|}{ Parameters for the monitored ion transition } \\
\hline Name & Retention time & $\begin{array}{l}\text { Parent } \\
\text { anion > frag- } \\
\text { ment anion }\end{array}$ & Q1 Pre-bias [V] & $\mathrm{CE}[\mathrm{V}]$ & $\begin{array}{l}\text { Q3 Pre- } \\
\text { bias } \\
{[\mathrm{V}]}\end{array}$ \\
\hline PFBA & 2.10 & $213.35>169.15$ & 14 & 9 & 30 \\
\hline MPFBA & 2.10 & $217.05>172.00$ & 15 & 13 & 23 \\
\hline PFPeA & 2.66 & $263.00>218.95$ & 18 & 8 & 22 \\
\hline PFBS & 2.70 & $299.05>99.00$ & 11 & 40 & 17 \\
\hline PFHxA & 3.00 & $313.30>269.10$ & 22 & 8 & 28 \\
\hline MPFHxA & 2.93 & $315.15>270.00$ & 12 & 9 & 27 \\
\hline PFHpA & 3.40 & $363.15>318.95$ & 22 & 12 & 26 \\
\hline PFHxS & 3.40 & $398.85>99.05$ & 28 & 36 & 15 \\
\hline MPFHxS & 3.42 & $403.00>103.10$ & 15 & 36 & 20 \\
\hline PFOA & 3.90 & $413.00>369.05$ & 15 & 10 & 17 \\
\hline MPFOA & 3.90 & $416.85>371.95$ & 15 & 10 & 24 \\
\hline PFNA & 4.42 & $463.10>418.90$ & 17 & 11 & 29 \\
\hline PFOS & 4.40 & $498.95>99.15$ & 18 & 41 & 21 \\
\hline MPFOS & 4.50 & $502.95>99.00$ & 20 & 40 & 19 \\
\hline PFDA & 5.00 & $513.00>468.90$ & 36 & 10 & 30 \\
\hline MPFDA & 5.00 & $515.00>469.90$ & 20 & 12 & 22 \\
\hline PFUdA & 5.50 & $563.20>519.10$ & 40 & 12 & 21 \\
\hline MPFUdA & 5.50 & $564.60>519.85$ & 20 & 13 & 24 \\
\hline PFDS & 5.40 & $598.90>99.10$ & 22 & 49 & 22 \\
\hline PFDoA & 5.90 & $613.00>568.85$ & 22 & 12 & 26 \\
\hline MPFDoA & 5.90 & $614.80>569.85$ & 22 & 12 & 26 \\
\hline PFTrDA & 6.30 & $662.80>618.90$ & 24 & 12 & 20 \\
\hline PFTeDA & 6.70 & $713.00>668.95$ & 26 & 12 & 30 \\
\hline PFHxDA & 7.30 & $812.70>768.85$ & 30 & 15 & 36 \\
\hline PFODA & 7.75 & $912.60>868.75$ & 34 & 15 & 40 \\
\hline \multicolumn{6}{|l|}{ MS/MS operation parameters } \\
\hline Interface temperature $\left[{ }^{\circ} \mathrm{C}\right]$ & & & 300 & & \\
\hline Desolvation line temperature $\left[{ }^{\circ} \mathrm{C}\right]$ & & & 250 & & \\
\hline Nebulizing gas flow $\left[\mathrm{L} \mathrm{min}^{-1}\right]$ & & & 3 & & \\
\hline Heating gas flow $\left[\mathrm{L} \mathrm{min}^{-1}\right]$ & & & 10 & & \\
\hline Heating block $\left[{ }^{\circ} \mathrm{C}\right]$ & & & 350 & & \\
\hline Drying gas flow $\left[\mathrm{L} \mathrm{min}^{-1}\right]$ & & & 10 & & \\
\hline
\end{tabular}

$C E$ collision energy, $Q 1$ and $Q 3$ Pre-bias-quadruple pre-rod bias voltage

\section{Sample Preparation Optimization}

Sample preparation was a significant part of samples analysis. Firstly, two types of equipment were used to perform solid phase extraction-manual and automated systems. Results of these tests were analyzed based on extraction recoveries for all analytes without matrix. The extraction recoveries of automated and manual systems were $60-105 \%$ and $20-98 \%$, respectively. (Detailed results of mean recoveries [\%] for automatic and manual systems, respectively, were as follows: PFBA: 96 and 79, PFPeA: 93 and 64, L-PFBS: 64 and 26, PFHxA: 83 and 54, PFHpA: 60 and 20, L-PFHxS: 63 and 27, PFOA: 104 and 98, PFNA: 101 and
98, L-PFOS: 100 and 58, PFDA: 87 and 77, PFUdA: 102 and 84, L-PFDS: 101 and 62, PFDoA: 96 and 77, PFTrDA: 98 and 88, PFTeDA: 76 and 69, PFHxDA: 98 and 89, PFODA: 92 and 70, MPFBA: 105 and 95, MPFHxA 59 and 23, MPFHxS: 65 and 29, MPFOA: 95 and 82, MPFOS: 93 and MPFDA: 95 and 84, MPFDoA: 102 and 88, MPFUdA: 95 and 81.) Regarding the assay precision, RSDs were generally lower than $10 \%$.

In addition to higher recovery, the time of sample preparation should be taken into consideration. The optimal flow rate of the sample is necessary, which causes significant time delays for sample loading in the SPE system. The use of a manual system required continuous laboratory supervision 


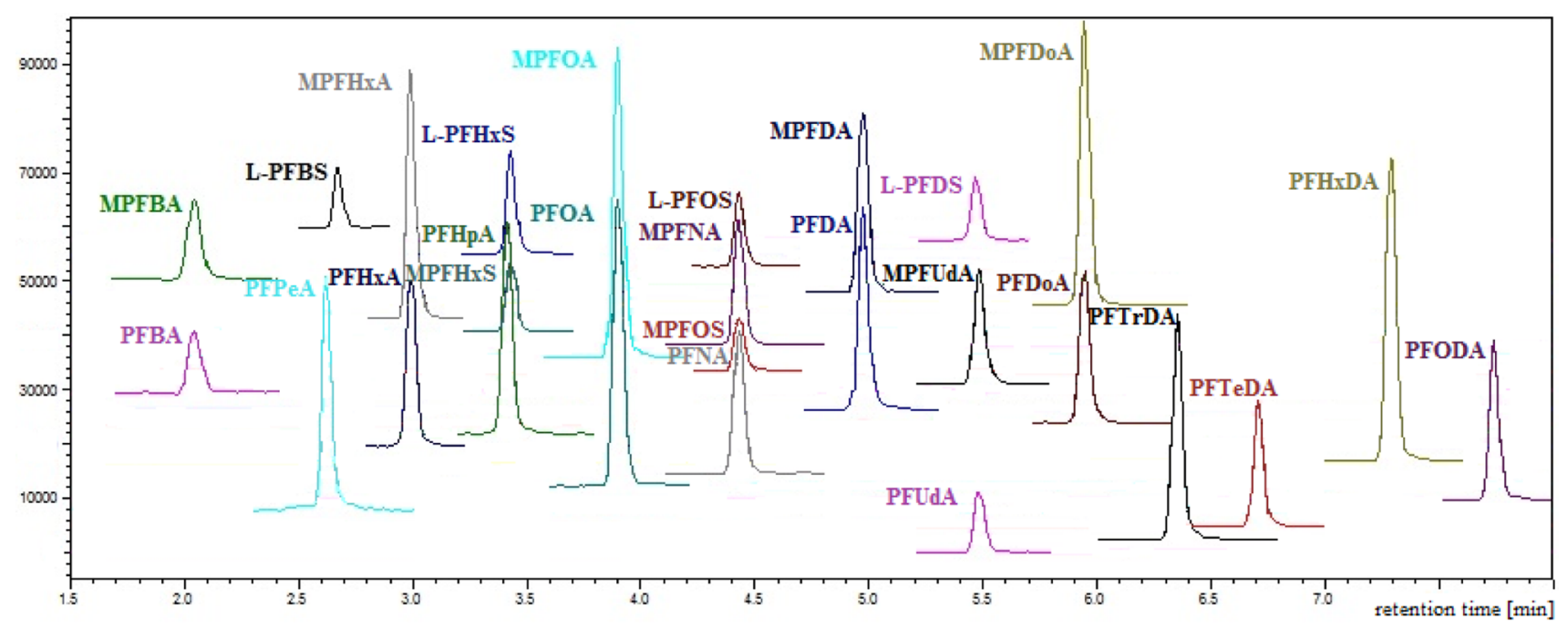

Fig. 1 Chromatogram of PFASs (10 $\mathrm{ng} \mathrm{mL}^{-1}$ in $\mathrm{MeOH}$ ) analysis with UHPLC/MS-MS using conditions described in Table 1

to control the flow rate of the sample and possible clogging of the bed. Meanwhile, when using the automatic system the above difficulties were not observed. Moreover, the automated SPE system has a number of benefits, including reduction in personnel exposure to solvent, increasing safety, better reproducibility, and handling most samples reliably and less attention is required for good results. For these reasons, an automated system sample preparation procedure was finally selected.

\section{Method Validation}

Based on analysis of working standard solutions in optimal conditions, calibration curves were prepared. Regression coefficients and selected parameters of validation are shown in Table 2. The obtained results are satisfactory, and it was proven that the proposed method is suitable for analysis of available perfluoroalkyl substances in sediments. In order to use the calibration curve method, recovery of analytes for real samples should be included.

In MS/MS detection, the signals for analytes can either be suppressed or enhanced by the matrix. As a consequence, it can result in the loss of sensitivity and precision. This applies in particular for sediment samples that have different morphological forms or loading of organic compounds. To check the effect of the matrix, three real sediment samples were prepared using the procedure described in "Sample Handling and Preparation" and analyzed with UHPLC-MS/ MS. Based on the area of the peaks, the recovery for eight labeled standards was calculated (see Table 3). The recoveries [\%] of analytes for samples including sample without matrix, sediment 1 , sediment 2 and sediment 3 ranged 59.0 (MPFHxA)-104.6 (MPFBA), 40.1 (MPFHxA)-103.3 (MPFDA), 8.62 (MPFHxA)-29.1 (MPFDA) and 19.27
(MPFBA)-30.23 (MPFOA), respectively. The labeled standards usually co-elute with the homologue analytes and are subjected to almost identical recovery and also matrix effect. As it can be expected, recoveries of analytes depend on the matrix type (sediments $1,2,3$ ). This suggests that the use of labeled standards is necessary to correct for the recovery and eventually matrix effect. The results show that the method is extremely inconsistent in certain real samples. In this study, only recoveries of analytes for the sediment 1 sample were acceptable.

The intra- and inter-day precision and recovery for sediment 1 with the addition of IS are summarized in Table 4. For all PFASs, the method detection limits (MDLs) were calculated. Based on the data, it should be noticed that storage conditions may affect the obtained result. This can be due to the extraction of the determined compounds from the materials used during the analysis (e.g., caps, vialsthey must be made of glass). This was also observed during sample preparation (leaching of PFASs from the materials from which the extraction devices are made). It is important to carry out a blank analysis subjected to identical sample storage and preparation conditions.

\section{Analysis of Environmental Samples}

The proposed analytical method can be used for the analysis of PFASs in sediments using labeled standards (see example of chromatogram for real samples, Fig. 2). However, not all homologue standards for PFASs are commercially available and to reduce costs, eight labeled standards were chosen for analysis. Therefore, the response factors (RF) for all available PFASs and labeled compounds were calculated (see Table 5). The choice of a labeled substance as an IS depended on several factors such as retention time of 
Table 2 Basic validation parameters of the PFASs determination method

\begin{tabular}{|c|c|c|c|c|c|c|c|c|}
\hline \multirow[t]{2}{*}{$\begin{array}{l}\text { Validation } \\
\text { parameters of } \\
\text { PFASs }\end{array}$} & \multicolumn{2}{|c|}{$\begin{array}{l}\text { Coefficient of } \\
\text { calibration curve } \\
(y=a x+b)\end{array}$} & \multicolumn{2}{|l|}{ Linearity } & \multirow[t]{2}{*}{$\mathrm{LOD}\left[\mathrm{ng} \mathrm{mL}{ }^{-1}\right]$} & \multirow[t]{2}{*}{$\begin{array}{l}\text { LOQ } \\
(3 \times \text { LOD }) \\
{\left[\mathrm{ng} \mathrm{mL}^{-1}\right]}\end{array}$} & \multicolumn{2}{|l|}{ Repeatability } \\
\hline & $a$ & $b$ & $\begin{array}{l}\text { Regression } \\
\text { coefficient } \\
\left(R^{2}\right)\end{array}$ & $\begin{array}{l}\text { Min-max } \\
{\left[\mathrm{ng} \mathrm{mL}^{-1}\right]}\end{array}$ & & & $\begin{array}{l}\text { Coefficient of } \\
\text { variation }(\mathrm{CV}) \\
\text { for the calibration } \\
\text { solution }[\%]\end{array}$ & $\begin{array}{l}\text { Expanded } \\
\text { uncertainty } U \\
(k=2)\end{array}$ \\
\hline PFBA & $15,693,957$ & 44,853 & 0.9608 & $0.13-12.5$ & 0.044 & 0.13 & $0.90-7.1$ & 2.4 \\
\hline PFPeA & $38,329,496$ & 71,187 & 0.9874 & $0.22-25$ & 0.074 & 0.22 & $0.49-5.8$ & 0.64 \\
\hline PFBS & $6,579,578$ & 11,444 & 0.9764 & $0.21-25$ & 0.069 & 0.21 & $0.99-7.5$ & 0.72 \\
\hline PFHxA & $4,585,702$ & 6575 & 0.9798 & $0.31-25$ & 0.10 & 0.31 & $1.3-4.4$ & 0.93 \\
\hline PFHpA & $17,539,073$ & 15,396 & 0.9357 & $0.20-25$ & 0.066 & 0.20 & $0.38-7.0$ & 1.4 \\
\hline PFHxS & $15,378,605$ & 19,739 & 0.9911 & $0.21-25$ & 0.070 & 0.21 & $0.92-6.3$ & 1.1 \\
\hline PFOA & $23,274,351$ & 37,183 & 0.9926 & $0.12-12.5$ & 0.039 & 0.12 & $1.4-6.8$ & 1.4 \\
\hline PFNA & $21,418,968$ & 36,562 & 0.9859 & $0.13-12.5$ & 0.043 & 0.13 & $0.60-6.9$ & 0.55 \\
\hline PFOS & $14,621,430$ & 17,802 & 0.9953 & $0.057-5$ & 0.019 & 0.057 & $0.37-8.5$ & 0.86 \\
\hline PFDA & $11,997,483$ & 15,940 & 0.9929 & $0.12-12.5$ & 0.039 & 0.12 & $0.40-7.2$ & 1.1 \\
\hline PFUdA & $1,576,660$ & 795 & 0.9809 & $1.4-25$ & 0.46 & 1.4 & $0.89-5.6$ & 1.4 \\
\hline PFDS & $13,918,696$ & 14,196 & 0.9944 & $0.034-5$ & 0.011 & 0.034 & $0.45-5.7$ & 2.8 \\
\hline PFDoA & $15,659,538$ & 10,642 & 0.9875 & $0.11-12.5$ & 0.037 & 0.11 & $2.5-6.7$ & 1.9 \\
\hline PFTrDA & $19,637,116$ & 16,240 & 0.9840 & $0.089-12.5$ & 0.030 & 0.089 & $1.3-9.8$ & 1.7 \\
\hline PFTeDA & $15,607,566$ & 9953 & 0.9937 & $0.062-5$ & 0.021 & 0.062 & $0.98-9.6$ & 0.67 \\
\hline PFHxDA & $25,228,081$ & 14,051 & 0.9867 & $0.10-12.5$ & 0.034 & 0.10 & $0.29-6.5$ & 1.9 \\
\hline PFODA & $23,498,314$ & 19,691 & 0.9887 & $0.082-12.5$ & 0.027 & 0.082 & $0.49-4.7$ & 2.8 \\
\hline
\end{tabular}

$L O D$ limit of detection, $L O Q$ limit of qualification

Table 3 Recovery of analytes [\%] for water and three sediment samples, with the addition of eight internal standards (IS) in the amount of $5 \mathrm{ng}$ each

\begin{tabular}{|c|c|c|c|c|c|c|c|c|}
\hline \multirow[t]{2}{*}{ Added IS } & \multicolumn{2}{|c|}{$\begin{array}{l}\text { Without sediment } \\
\text { matrix: water } \\
n=5\end{array}$} & \multicolumn{2}{|c|}{ Sediment $1 n=10$} & \multicolumn{2}{|c|}{ Sediment $2 n=3$} & \multicolumn{2}{|c|}{ Sediment $3 n=3$} \\
\hline & Mean & RSD & Mean & RSD & Mean & RSD & Mean & RSD \\
\hline MPFBA & 104.6 & 2.1 & 56.2 & 7.1 & 9.40 & 0.76 & 19.27 & 0.37 \\
\hline MPFHxA & 59.0 & 2.3 & 40.1 & 1.5 & 8.62 & 0.12 & 21.04 & 0.59 \\
\hline MPFHxS & 64.5 & 2.5 & 55.19 & 0.75 & 9.4 & 1.7 & 18.41 & 0.28 \\
\hline MPFOA & 95.2 & 2.5 & 64.42 & 0.73 & 17.1 & 1.7 & 30.23 & 0.48 \\
\hline MPFOS & 92.6 & 2.3 & 71.6 & 3.1 & 17.7 & 2.7 & 21.01 & 1.54 \\
\hline MPFDA & 95.1 & 4.1 & 103.3 & 1.3 & 29.1 & 2.7 & 36.56 & 0.50 \\
\hline MPFUdA & 95.1 & 2.6 & 74.6 & 2.2 & 28.4 & 7.7 & 29.23 & 0.33 \\
\hline MPFDoA & 101.5 & 2.1 & 71.3 & 1.6 & 22.1 & 3.7 & 29.99 & 0.65 \\
\hline
\end{tabular}

$R S D$ relative standard deviation, $n$ number of samples substances, similarity of chemical structure and a value of detector response of about one (see bold response factors in Table 5).

Analysis of the 17 sediment samples for PFASs content shows that the sum of PFASs ( $\sum$ PFASs) in the surface sediments was the highest at two sampling points $\left(19.2 \pm 1.7\right.$ and $6.51 \pm 0.24 \mu \mathrm{g} \mathrm{g}^{-1}$ d.w. $)$ and the lowest at another two points $\left(28.2 \pm 2.7\right.$ and $18.6 \pm 1.6 \mathrm{ng} \mathrm{g}^{-1}$ d.w. $)$. In the analyzed samples, PFBA was the major component representing up to $99 \%$ of the $\sum$ PFASs. In general, most of the analyzed PFASs compounds were below the method detection limit. In the tested samples, only PFDS represents the PFSAs group and was measured at levels from < LOQ to $118 \pm 11 \mathrm{ng} \mathrm{g}^{-1}$ d.w. Only in few sediment samples compounds that were not previously determined (PFHxDA, PFODA, PFDS) were identified but below MDL. However, this indicates that they should be taken into consideration for investigation. 
Table 4 Validation parameters of PFASs determination methods based on real samples

\begin{tabular}{|c|c|c|c|c|c|c|c|c|c|c|}
\hline \multirow[t]{3}{*}{ Compounds } & \multicolumn{4}{|c|}{ Intra-day precision and recovery } & \multicolumn{4}{|c|}{ Inter-day precision and recovery } & \multirow[t]{3}{*}{ MDL $\left[\mathrm{pg} \mathrm{g}^{-1}\right]$} & \multirow[t]{3}{*}{ IS } \\
\hline & \multicolumn{2}{|c|}{$12.5 \mathrm{ng} \mathrm{mL}^{-1}$} & \multicolumn{2}{|c|}{$0.5 \mathrm{ng} \mathrm{mL}^{-1}$} & \multicolumn{2}{|c|}{$12.5 \mathrm{ng} \mathrm{mL}^{-1}$} & \multicolumn{2}{|c|}{$0.5 \mathrm{ng} \mathrm{mL}^{-1}$} & & \\
\hline & Recovery & RSD & Recovery & RSD & Recovery & RSD & Recovery & RSD & & \\
\hline PFBA & 112.0 & 5.8 & 101.80 & 0.87 & 106.0 & 2.9 & 107.9 & 3.8 & 0.35 & MPFBA \\
\hline PFPeA & 100.69 & 0.77 & 98.0 & 1.0 & 93.7 & 3.2 & 92.1 & 4.1 & 0.59 & MPFOA \\
\hline PFBS & 101.7 & 0.84 & 107.1 & 3.4 & 111.0 & 5.4 & 105.6 & 2.7 & 0.55 & MPFHxS \\
\hline PFHxA & 102.3 & 1.2 & 87.0 & 7.3 & 116.0 & 8.8 & 114.0 & 9.7 & 0.81 & MPFHxA \\
\hline PFHpA & 101.22 & 0.62 & 102.9 & 1.4 & 109.9 & 8.1 & 99.48 & 0.26 & 0.52 & MPFHxA \\
\hline PFHxS & 101.30 & 0.64 & 86.0 & 9.4 & 102.2 & 1.1 & 90.2 & 7.5 & 0.56 & MPFHxS \\
\hline PFOA & 98.20 & 0.93 & 92.4 & 4.0 & 10.1 & 3.0 & 108.6 & 9.4 & 0.31 & MPFOA \\
\hline PFNA & 98.51 & 0.78 & 108.3 & 4.0 & 111 & 8.6 & 108.1 & 3.9 & 0.35 & MPFHхА \\
\hline PFOS & 103.3 & 1.6 & 94.8 & 2.7 & 109.4 & 4.5 & 94.3 & 8.6 & 0.15 & MPFOS \\
\hline PFDA & 104.3 & 2.1 & 95.1 & 2.5 & 106.0 & 2.9 & 103.4 & 1.7 & 0.31 & MPFDA \\
\hline PFUdA & 105.9 & 2.9 & 111.0 & 9.8 & 114.0 & 6.7 & 112.0 & 6.7 & 3.7 & MPFUdA \\
\hline PFDS & 103.3 & 1.6 & 107.3 & 3.5 & 94.9 & 2.6 & 100.63 & 0.31 & 0.090 & MPFOS \\
\hline PFDoA & 103.7 & 1.8 & 107.1 & 3.4 & 109.4 & 4.5 & 109.8 & 4.0 & 0.30 & MPFDoA \\
\hline PFTrDA & 106.9 & 3.4 & 103.8 & 1.8 & 109.5 & 8.9 & 114.0 & 6.9 & 0.24 & MPFUdA \\
\hline PFTeDA & 97.6 & 1.2 & 94.1 & 3.1 & 108.9 & 4.3 & 114.0 & 6.7 & 0.17 & MPFUdA \\
\hline PFHxDA & 107.3 & 3.5 & 94.1 & 3.0 & 117.0 & 7.9 & 113.0 & 5.9 & 0.27 & MPFDoA \\
\hline PFODA & 92.9 & 0.34 & 106.2 & 3.0 & 105.3 & 2.6 & 105.3 & 1.7 & 0.22 & MPFDoA \\
\hline
\end{tabular}

Intra- and inter-day precision and recovery [\%] for two level of compounds concentration, number of samples $n=5$

$M D L$ method detection limit, IS internal standard used in analysis, $R S D$ relative standard deviation

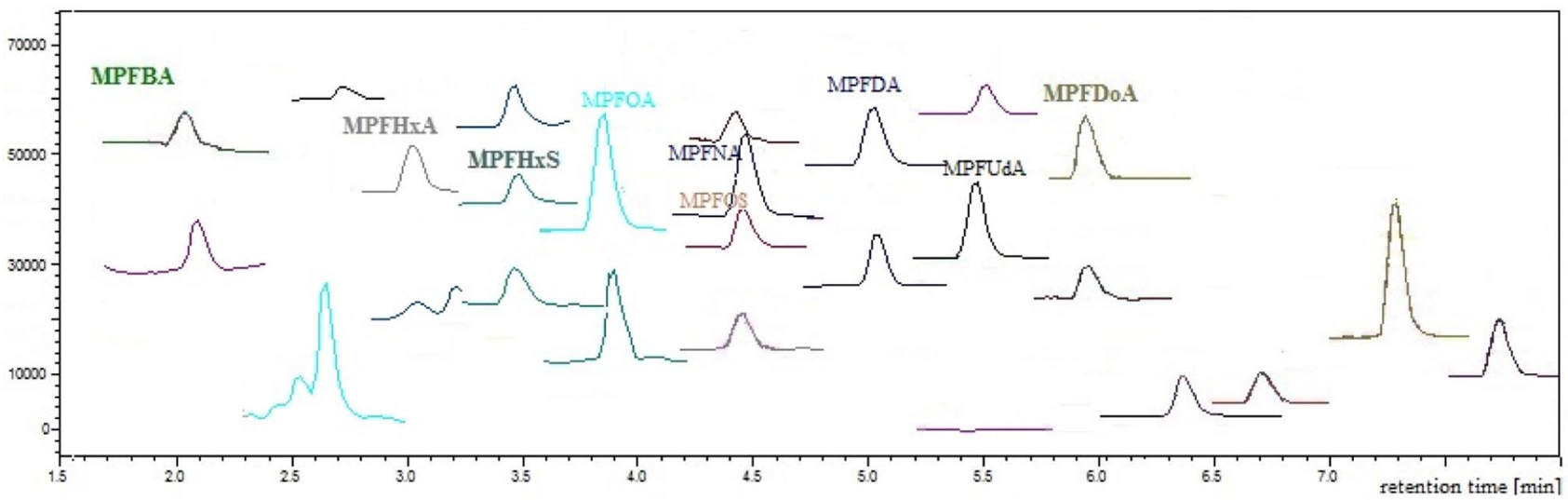

Fig. 2 Chromatogram obtained for sediment sample prepared using the proposed method and analyzed with UHPLC/MS-MS using conditions described in Table 1

\section{Conclusions}

A novel analytical method with good selectivity, sensitivity, reparability and recovery was developed and validated for determination of 17 PFASs ( 13 acids and 4 sulfonates compounds) in sediment. In previous studies, only few PFASs were analyzed. For example, Yang et al. [4] determined 10 PFASs in sediments and water. There, MDL and
MQL values for individual PFASs (10-20 $\mathrm{pg} \mathrm{g}^{-1}$ ) were about ten times higher than the results obtained in this study.

Generally, in the collected sediment samples, compounds from the group of PFSAs and PFCAs occur at low levels. High concentrations of $\sum$ PFASs were found only in two samples taken at the east and northeast side from the mouth of the Vistula River, where it is entering to the waters of the Gulf of Gdansk. Higher contamination of investigated 
Table 5 Response factors for PFASs and labeled standards, where bold font-selected internal standards

\begin{tabular}{|c|c|c|c|c|c|c|c|c|}
\hline \multirow[t]{2}{*}{ Name } & \multicolumn{8}{|c|}{ Response factor (RF) } \\
\hline & MPFBA & MPFHxS & MPFHxA & MPFOA & MPFOS & MPFDA & MPFDoA & MPFUdA \\
\hline PFBA & 0.89 & 1.2 & 0.75 & 0.51 & 1.0 & 1.0 & 0.74 & 0.80 \\
\hline PFPeA & 1.9 & 2.9 & 1.8 & 1.2 & 2.4 & 2.4 & 1.8 & 1.9 \\
\hline PFBS & 0.33 & 0.50 & 0.31 & 0.21 & 0.41 & 0.41 & 0.30 & 0.33 \\
\hline PFHxA & 0.23 & 0.34 & 0.21 & 0.14 & 0.29 & 0.28 & 0.21 & 0.23 \\
\hline PFHpA & 0.85 & 1.3 & 0.82 & 0.54 & 1.1 & 1.1 & 0.80 & 0.86 \\
\hline PFHxS & 0.76 & 1.1 & 0.71 & 0.48 & 0.95 & 0.94 & 0.70 & 0.75 \\
\hline PFOA & 1.2 & 1.7 & 1.1 & 0.73 & 1.4 & 1.4 & 1.1 & 1.1 \\
\hline PFNA & 1.1 & 1.6 & 1.0 & 0.68 & 1.3 & 1.3 & 0.99 & 1.1 \\
\hline PFOS & 0.72 & 1.1 & 0.67 & 0.45 & 0.90 & 0.90 & 0.67 & 0.72 \\
\hline PFDA & 0.59 & 0.89 & 0.56 & 0.37 & 0.74 & 0.75 & 0.55 & 0.59 \\
\hline PFUdA & 0.075 & 0.11 & 0.072 & 0.048 & 0.10 & 0.10 & 0.071 & 0.076 \\
\hline PFDS & 0.67 & 1.0 & 0.64 & 0.43 & 0.85 & 0.85 & 0.63 & 0.68 \\
\hline PFDoA & 0.75 & 1.1 & 0.71 & 0.48 & 0.95 & 0.95 & 0.71 & 0.76 \\
\hline PFTrDA & 0.94 & 1.4 & 0.90 & 0.60 & 1.2 & 1.2 & 0.89 & 0.96 \\
\hline PFTeDA & 0.74 & 1.1 & 0.71 & 0.48 & 0.95 & 0.67 & 0.70 & 0.76 \\
\hline PFHxDA & 1.2 & 1.8 & 1.1 & 0.77 & 1.5 & 1.5 & 1.1 & 1.2 \\
\hline PFODA & 1.1 & 1.7 & 1.1 & 0.72 & 1.4 & 1.4 & 1.07 & 1.1 \\
\hline
\end{tabular}

sediments may be connected with hydrogeological conditions at the sampling area. However, the obtained research results require more detailed analysis.

Acknowledgements This work has been financially supported by the Polish Ministry of Science and Higher Education (project MN 01-0391/08/322). The authors would like to thank for support to Shimpol (Poland).

Open Access This article is licensed under a Creative Commons Attribution 4.0 International License, which permits use, sharing, adaptation, distribution and reproduction in any medium or format, as long as you give appropriate credit to the original author(s) and the source, provide a link to the Creative Commons licence, and indicate if changes were made. The images or other third party material in this article are included in the article's Creative Commons licence, unless indicated otherwise in a credit line to the material. If material is not included in the article's Creative Commons licence and your intended use is not permitted by statutory regulation or exceeds the permitted use, you will need to obtain permission directly from the copyright holder. To view a copy of this licence, visit http://creativecommons.org/licenses/by/4.0/.

\section{References}

1. Cousins IT, Vestergren R, Wang Z, Scheringer M, McLachlan MS (2016) The precautionary principle and chemicals management: the example of perfluoroalkyl acids in groundwater. Environ Int 94:331-340

2. OECD (2006) Lists of PFSAS, PFAS, PFCA, related compounds and chemicals that may degrade to PFCA. Jm Mono 15:1-157

3. De Felip E, Abballe A, Albano FL, Battista T, Carraro V, Conversano M, Franchini S, Giambanco L, Iacovella N, Ingelido AM, Maiorana A, Maneschi F, Marra V, Mercurio A, Nale R, Nucci B, Panella V, Pirola F, Porpora MG, Procopio E, Suma
N, Valentini S, Valsenti L, Vecchič V (2015) Current exposure of Italian women of reproductive age to PFSAS and PFCAS: a human biomonitoring study. Chemosphere 137(1):8

4. Yang L, Zhu L, Liu Z (2011) Occurrence and partition of perfluorinated compounds in water and sediment from Liao River and Taihu Lake, China. Chemosphere 83:806-814

5. Chen H, Reinhard M, Nguyen VT, Gin KYH (2016) Reversible and irreversible sorption of perfluorinated compounds (PFASs) by sediments of an urban reservoir. Chemosphere 144:1747-1753

6. Lin AYC, Panchangam SC, Tsai YT, Yu TH (2014) Occurrence of perfluorinated compounds in the aquatic environment as found in science park effluent, river water, rainwater, sediments, and biotissues. Environ Monit Assess 186:3265-3275

7. Lopez-Antia A, Dauwe T, Meyer J, Maes K, Bervoets L, Eens M (2017) High levels of PFSAS in eggs of three bird species in the neighbourhood of a fluoro-chemical plant. Ecotoxicol Environ Saf 139:65-171

8. Castiglioni S, Valsecchi S, Polesello S, Rusconi M, Melis M, Palmiotto M, ManentiA DE, Zuccato E (2015) Sources and fate of perfluorinated compounds in the aqueous environment and in drinking water of a highly urbanized and industrialized area in Italy. J Hazard Mater 282:51-60

9. Lu Z, Song L, Zhao Z, Ma Y, Wang J, Yang H, Ma H, Cai M, Codling G, Ebinghaus R, Xie Z, Giesy JP (2015) Occurrence and trends in concentrations of perfluoroalkyl substances (PFASs) in surface waters of eastern China. Chemosphere 119:820-827

10. Higgins CP, Luthy RG (2006) Sorption of perfluorinated surfactants on sediments. Environ Sci Technol 40:7251-7256

11. EFSA (2008) Perfluorooctanesulfonate (PFSAS), perfluorooctanoic acid (PFCAS) and their salts. EFSA J 653:1-131

12. Corsini E, Luebke RW, Germolec DR, De Witt JC (2014) Perfluorinated compounds: emerging POPs with potential immunotoxicity. Toxicol Lett 230(2):263-270

13. D'Hollander W, Roosens L, Covaci A, Cornelis Ch, Reynders H, van Campenhout K, de Voogt P, Bervoets L (2010) Brominated flame retardants and perfluorinated compounds in indoor dust 
from homes and offices in Flanders, Belgium. Chemosphere $81: 478-487$

14. Joensen UN, Bossi R, Leffers H, Jensen AA, Skakkebaek NE, Jørgensen N (2009) Do perfluoroalkyl compounds impair human semen quality? Environ Health Perspect 117:923-927

15. ASTSWMO (2015) Perfluorinated chemicals (PFASs): perfluorooctanoic acid (PFCAs) and perfluorooctane sulfonate (PFSAs) information paper. The Association of State and Territorial Solid Waste Management Officials, Gdansk

16. Surma M, Wiczkowski W, Cieślik E, Zieliński H (2015) Method development for the determination of PFCAS and PFSAS in honey based on the dispersive solid phase extraction (d-SPE) with micro-UHPLC-MS/MS system. Microchem J 121:150-156

17. Zushi Y, Tamada M, Kanai Y, Masunaga S (2010) Time trends of perfluorinated compounds from the sediment core of Tokyo Bay, Japan (1950s-2004). Environ Pollut 158:756-763
18. Zhao Z, Xie Z, Tang J, Zhang G, Ebinghaus R (2015) Spatial distribution of perfluoroalkyl acids in surface sediments of the German Bight, North Sea. Sci Total Environ 511:145-152

19. Konieczka P, Namieśnik J (2009) Quality assurance and quality control in the analytical chemical laboratory: a practical approach. CRC Press, Boca Raton

Publisher's Note Springer Nature remains neutral with regard to jurisdictional claims in published maps and institutional affiliations. 